\title{
Otofaciocervical syndrome: a sporadic patient supports splitting from the branchio-oto-renal syndrome
}

\author{
Bruno Dallapiccola, Rita Mingarelli
}

\begin{abstract}
A sporadic patient with OFC syndrome is described. Distinguishing features were a long face with narrow nose, high arched palate, prominent and dysmorphic ears, long neck, sloping shoulders and clavicles, winged, low, and laterally set scapulae, tetralogy of Fallot, and deafness secondary to cochlear malformation. Some features present in the original family, including lateral cervical fistulae, have suggested that OFC syndrome could be a variant of BOR syndrome. The absence of preauricular tags, lacrimal duct stenosis, and renal malformations, and the presence of distinct facial and radiographic findings and markedly downward sloping shoulders in the present patient support OFC syndrome being a unique, clinically recognisable entity.
\end{abstract}

(f Med Genet 1995;32:816-818)

Otofaciocervical syndrome (OFS) was originally described by Fara $e t a l^{1}$ in a man and in four of his seven children. Distinguishing features were short stature, long face with a relatively broad forehead and narrow mandible and nose, sunken nasal roots, high arched palate, prominent ears with large conchae, preauricular fistulas, lateral cervical fistulas in some patients, long neck with downward sloping shoulders and clavicles, laterally displaced with winged scapulae, bilateral conductive hearing loss, and mild intellectual deficit. Although the combination of characteristic face, auricular abnormalities, hearing loss, and sloping shoulders is unique, the possibility has been discussed that OFCS is a variant of the branchio-oto-renal (BOR) syndrome. ${ }^{2}$ This suggestion was supported by a boy who had overlapping features of OFCS and BOR syndrome, including inability to raise the left arm, long neck, and sloping shoulders, ${ }^{3}$ and by a patient with lacrimal duct stenosis, preauricular fistula and tag, sloping shoulders, normal genitourinary system, and spina bifida occulta. ${ }^{4}$

We report a sporadic patient with the features of OFCS in whom the absence of most of the distinguishing characteristics of BOR syndrome supports the syndrome originally described by Fara $e t a l^{1}$ being a distinct, clinically recognisable entity.
Case report

The proband, a girl, the second child of nonconsanguineous, phenotypically normal parents, was born in the 37th week of gestation, after an uneventful pregnancy. An older sister is healthy. Birth weight was $2800 \mathrm{~g}$ (25th centile), length $47 \mathrm{~cm}$ (25th centile), and head circumference $33 \mathrm{~cm}$ (25th centile). The neonatal period was characterised by respiratory distress and cyanosis. Tetralogy of Fallot was diagnosed at 1 month of age, and surgically repaired at the ages of 5 and 7 years. Bilateral sensorineural deafness was diagnosed at 1 year.

This girl was first referred to us at the age of 13 years 2 months (fig 1 ). Height was $152 \mathrm{~cm}$ (between the 25th and 50th centile), weight $42 \mathrm{~kg}$ (between the $25 \mathrm{th}$ and $50 \mathrm{th}$ centile), and head circumference $52 \mathrm{~cm}$ ( $<50$ th centile). Clinical examination showed an elongated face with an inverted triangular shape, broad forehead, pinched nose, mildly upward slanted palpebral fissures, open lacrimal ducts, inturning upper lip, high arched palate, and malocclusion. The ears were prominent, slanted, and grossly dysmorphic, with large conchae and hypoplastic tragus, antitragus, and lobe, in the absence of preauricular fistulas and tags (fig 2). The neck appeared long, without branchial cleft, sinus, or cysts, but with posteriorly prominent cervical vertebrae. Shoulders and clavicles were markedly downward sloping and the scapulae winged and more laterally located than normal. Kyphosis and marked lumbar lordosis were also present. The fingers were thin and long and the hallux valgus bilaterally. Neurological evaluation and intellectual development were grossly normal.

An ultrasound examination of the abdominal organs disclosed morphologically normal and well positioned kidneys and normal liver, uterus, and ovaries. IVP was also normal.

A systematic $x$ ray skeletal survey showed a turricephalic skull, narrowing of the middle third of the face, a deep sella turcica, steep clivus, hyperpneumatised paranasal sinuses, and poor mastoid pneumatisation. A flattened glenoid cavity was found at the temporomandibular articulation. The shoulders were low. The straight and obliquely downward slanted clavicles were at the level of the fourth rib (fig 3). The scapulae were low and laterally set, with an anterior opening of the glenoid cavities. The spine showed a reduced AP diameter of $\mathrm{C} 1$ to $\mathrm{C} 4$, a trapezoidal shape of 

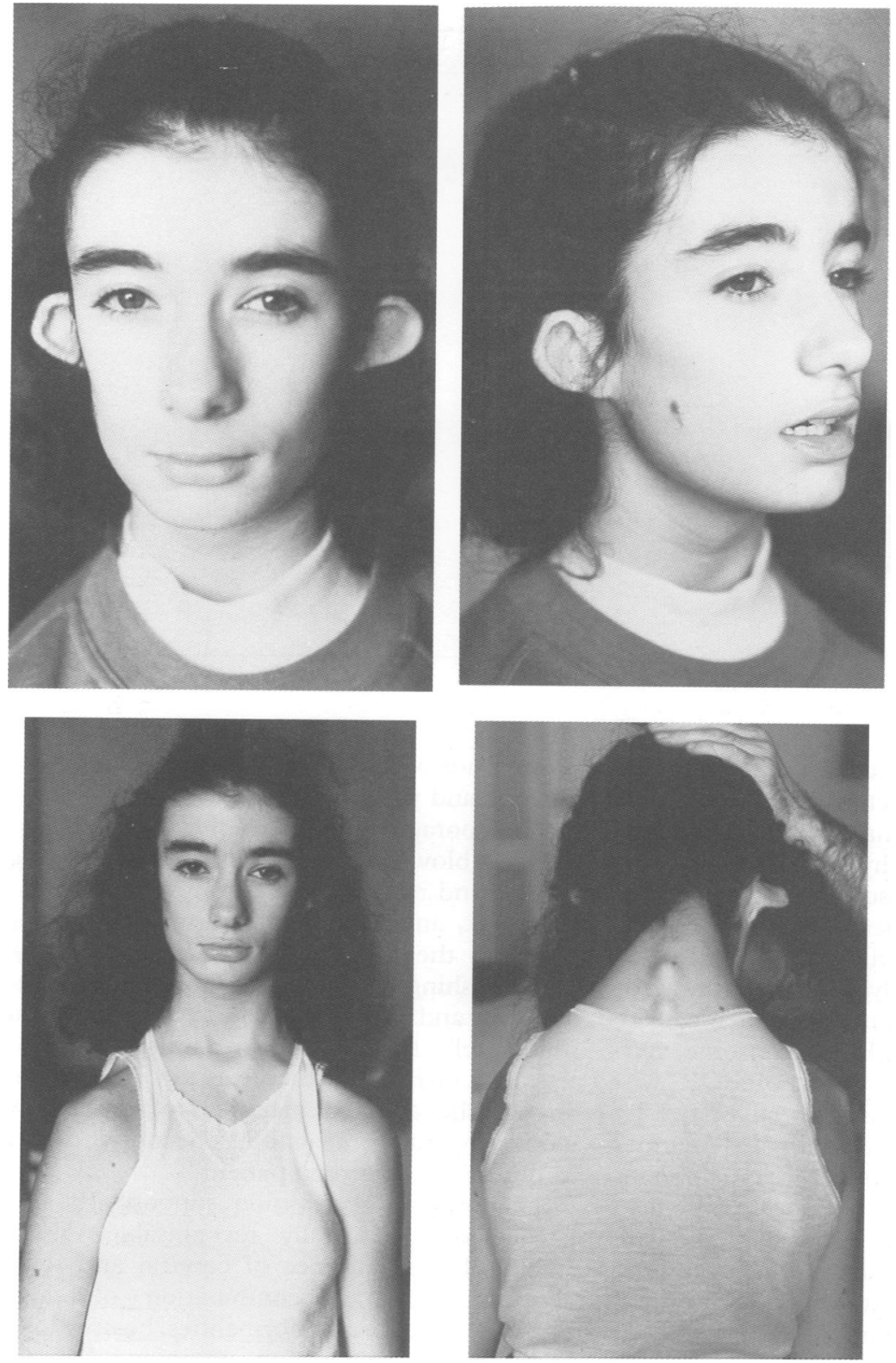

Figure 1 Four views of the OFCS patient showing characteristic facies with abnormal ears and sloping shoulders.

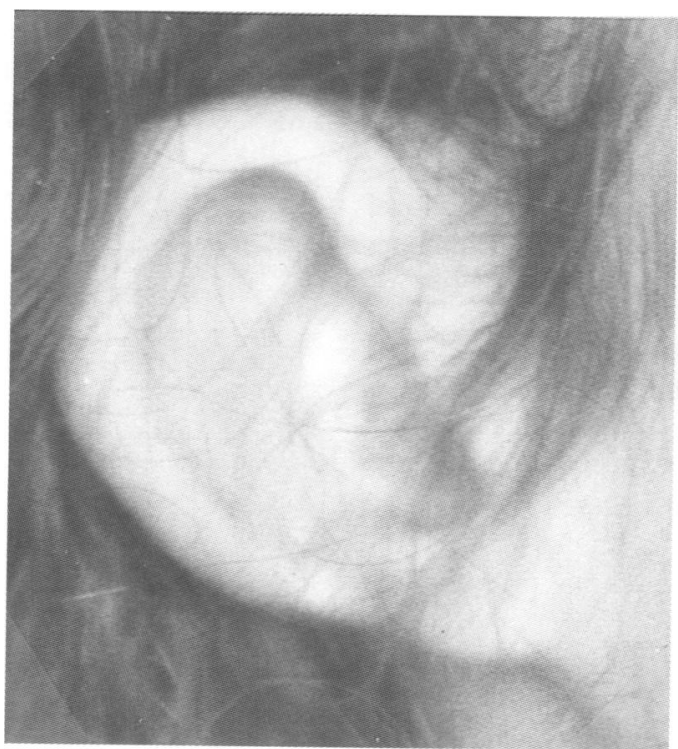

Figure 2 Right ear of proband.

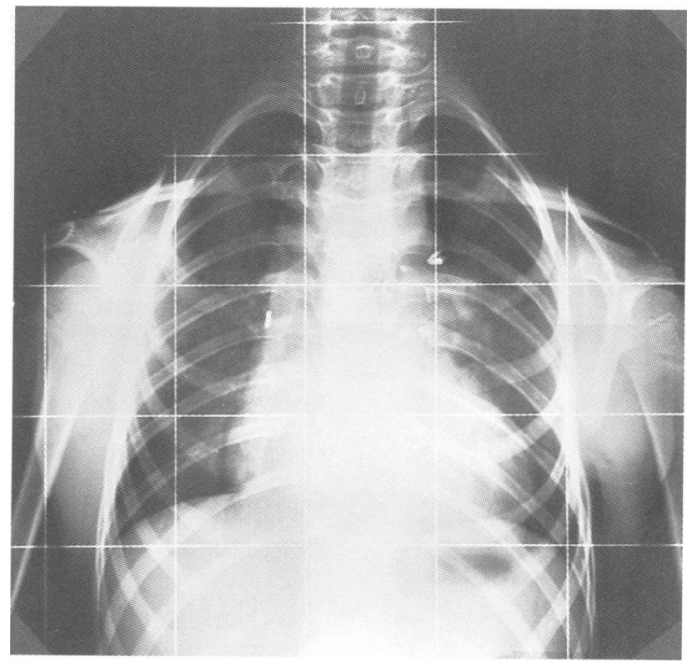

Figure 3 Radiograph showing depressed position of shoulders, clavicles at the level of the fourth rib, with outer ends running obliquely downwards.

C6 to D1 bodies, an enlarged vertebral canal, and mildly dysmorphic lumbar vertebrae. Acetabular angles were narrow with valgus hips, overtubulated long bones, and dysmorphic trapezium. Bone age was normal.

A CT scan of the inner ear disclosed bilaterally bipartite cochlea, absent lateral semicircular canals, and dilated vestibulum (fig 4).

Chromosomes were normal both on standard and high resolution analysis, including scrutiny of $8 \mathrm{q}$.

The association between facial abnormalities, oto-cervical defects, and tetralogy of Fallot prompted a search for microdeletion within the 22q11 region. Molecular analysis was carried out on genomic DNA obtained from leucocytes using probe HD7k and on metaphase spreads using fluorescent in situ hybridisation (FISH) with probe Sc11.1, basically according to Amati et al. ${ }^{5}$ No evidence of deficiency of region 22q11 was obtained in this patient.

\section{Discussion}

The family with abnormalities of the external ear, face, and neck originally described by Fara

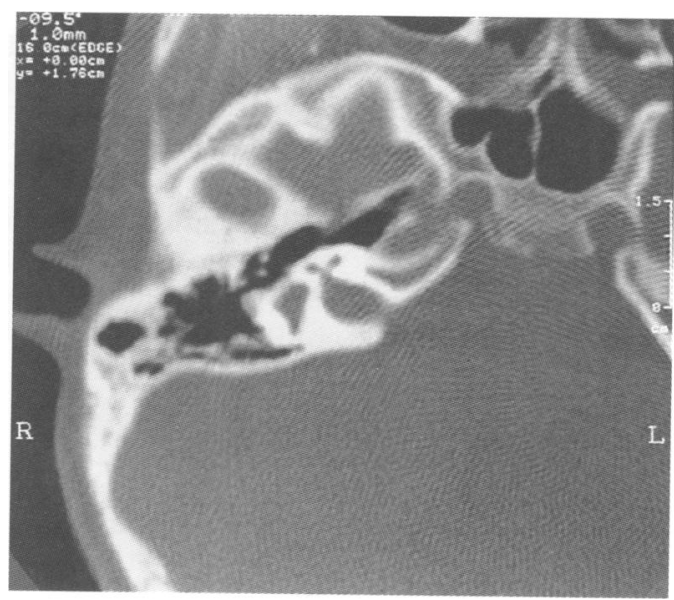

Figure $4 C T$ scan of inner ear showing bipartite cochlea absent lateral semicircular canal, and dilated vestibulum. 
Clinical findings in BOR syndrome, OCF syndrome, and in the present patient

\begin{tabular}{|c|c|c|c|}
\hline Clinical findings & $B O R$ & OCFS & Present patient \\
\hline $\begin{array}{l}\text { Craniofacial } \\
\text { Long and narrow facies } \\
\text { High arched palate } \\
\text { Aplasia/stenosis of lacrimal duct }\end{array}$ & $\begin{array}{l}+ \\
+ \\
+(10 \%)\end{array}$ & $\begin{array}{l}+ \\
+ \\
-\end{array}$ & $\begin{array}{l}+ \\
+ \\
-\end{array}$ \\
\hline $\begin{array}{l}\text { External ear anomalies } \\
\text { Helical/preauricular pits } \\
\text { Auditory system } \\
\text { Conductive hearing loss } \\
\text { Sensorineural hearing loss } \\
\text { Mixed hearing loss }\end{array}$ & $\begin{array}{l}+(30-60 \%) \\
+(70-80 \%) \\
+(30 \%) \\
+(20 \%) \\
+(50 \%)\end{array}$ & $\begin{array}{l}+ \\
+ \\
+ \\
-\end{array}$ & $\begin{array}{l}+ \\
- \\
- \\
+\end{array}$ \\
\hline Branchial cysts or fistulas & $+(60 \%)$ & + & - \\
\hline Hypoplastic cervical muscles & - & + & + \\
\hline Downward sloping shoulders and clavicles & - & + & + \\
\hline Winged/laterally located scapulae & - & + & + \\
\hline $\begin{array}{l}\text { Genitourinary system } \\
\text { Structural renal anomalies } \\
\text { Functional renal anomalies }\end{array}$ & $\begin{array}{l}+(12-20 \%) \\
+\end{array}$ & $\begin{array}{l}1 / 6 \\
-\end{array}$ & $\overline{-}$ \\
\hline Short stature & - & + & - \\
\hline Mild mental retardation & - & + & - \\
\hline
\end{tabular}

et $a l^{1}$ supported autosomal dominant inheritance and was characterised by prominent auricles with deep conchae, preauricular pits, lateral cervical fistulae, hypoplasia and weakness of the cervical musculature with an abnormal range of movements at the shoulders, peculiar radiographic findings, and conductive hearing loss. Admittedly, some of the otocervical features found in the patients were similar to those found in BOR syndrome, supporting OFCS being a variant of BOR syndrome. This overlap was also suggested by agenesis of one kidney in one affected member of the original family. However, preauricular tags and lacrimal duct stenosis were absent in this family. In addition, renal anomalies are common in BOR syndrome, in which shoulder abnormalities and short stature are not found.

To further support lumping these two conditions Pennie and Mares $^{3}$ reported a 7 year old boy who had true BOR syndrome with associated shoulder abnormalities. Notably, this patient showed inability to raise the left arm, while all other shoulder movements were normal. This is an unexpected finding in OFCS. In addition he had a long neck, narrow and sloping shoulders with a prominent free edge of the trapezium, and a high, laterally placed, winged left scapula. This is not a feature of OFCS in which scapulae project at the level of the axillae. Finally, the aural and facial characteristics were quite dissimilar to those of OFCS.

The clinical definition of the patient quoted by Gorlin $e t a l^{4}$ as a further example of OFCS is also difficult. In fact, the facial and aural features were not those expected in this syn- drome, nor was the presence of lacrimal duct stenosis and preauricular tag.

The sporadic patient studied by us shows the full blown features of OFCS, including clinical and radiographic craniofacial findings, ear, neck, and shoulder abnormalities. Compared to the patients of the original family, distinguishing features are absence of preauricular and cervical fistulae, hyporeflexia, and mild intellectual deficit. In addition she had tetralogy of Fallot, which was not reported in any of the affected members of the family studied by Fara $e t a l^{1}$ and has been found only in one BOR syndrome patient. ${ }^{6}$

The present observation supports the existence of a clinically recognisable OFCS (table). In the absence of cervical and renal abnormalities, this combination of characteristic facies, ear abnormalities, hearing loss, and sloping shoulders appears unique. Despite the presence of some overlapping features, on clinical grounds at least, OFCS seems to be separate from BOR syndrome.

This work was supported by ASM, Milan, European Community, BIOMED-1, and MURST $60 \%$.

1 Fara M, Chlupackova V, Hrivnakova J. Dysmorphia otofacio-cervicalis familiaris. Acta Chir Plast 1967;9:255-68. McKusick VA. Mendelian inheritance in man. Baltimore: John Hopkins University Press, 1994

3 Pennie BH, Mares HAM. Shoulder abnormalities in association with branchio-oto-renal dysplasia in a patient who also has familial joint laxity. Int $f$ Pediatr Otorhinowho also has familial joint

4 Gorlin RJ, Toriello HV, Cohen MM. Hereditary hearing loss and its syndromes. New York: Oxford University Press, 1995 : and its synd $100-2$.

5 Amati F, Mari A, Digilio MC, et al. 22q11 deletions in isolated and syndromic patients with tetralogy of Fallot. Hum Genet 1995;95:479-82.

6 Daggilas A, Antoniades K, Palasis S, Aidonis A. Branchiooto-renal dysplasia associated with tetralogy of Fallot. $\mathrm{Am}$ f Med Genet 1978;2:241-52. 